\title{
TRANSTORNO DO ESPECTRO AUTISTA - TEA
}

Fabiana Haro dos Santos, Mariana Aparecida Grillo

Universidade do Oeste Paulista - UNOESTE, curso de Pedagogia, Presidente Prudente, SP. E-mail:

fabianaharo@hotmail.com

\section{RESUMO}

Este artigo apresenta a definição, as características e as ações do professor por meio das práticas pedagógicas com crianças que apresentam o Transtorno do Espectro Autista. Tem como objetivo nortear a prática do professor da etapa de Ensino Fundamental I, que através da observação e estudos sobre o assunto compreenderá mais profundamente como trabalhar pedagogicamente com uma criança diagnosticada com Autismo, diagnóstico este, que depende de uma equipe multidisciplinar. $\mathrm{O}$ artigo foi realizado via pesquisa bibliográfica, exploratória e descritiva. Teve como resultado refletir sobre o TEA. A partir disso, pode-se concluir que a educação inclusiva é um desafio que requer uma mudança de olhar, de pensar e agir.

Palavras-chave: Transtorno do Espectro Autista. Professor. Práticas pedagógicas.

\section{SPECTRUM DISORDER OF AUTISTIC - TEA}

\begin{abstract}
This article presents the definition, teacher characteristics and actions through educational practices with children with Autism Spectrum Disorder. It aims to guide the practice of teacher of primary education stage I, through observation and studies on the subject will understand more deeply how to work pedagogically with a child diagnosed with Autism, this diagnosis, which relies on a multidisciplinary team. The article was conducted via literature, exploratory and descriptive research. It resulted reflect on the TEA. From this it can be concluded that inclusive education is a challenge that requires a change of look think and act.
\end{abstract}

Keywords: Disorder Autism Spectrum. Teacher. Pedagogical practices. 


\section{INTRODUÇÃO}

O Transtorno do Espectro Autista é um dos importantes temas debatidos em torno da área educacional na atualidade, portanto, tendo a necessidade de ser melhor discutido e compreendido.

O Transtorno do Espectro Autista é uma síndrome definida por alterações presentes desde muito cedo, isto significa que pode ser apresentada antes de três anos de idade, porém revela que cada criança é diferente e os sintomas podem aparecer antes desta idade, ou se tornarem mais visíveis ao longo de seu crescimento.

$$
\text { A criança apresenta } 0
$$
comprometimento com a comunicação, a socialização, e o uso da imaginação, fazendo com que a criança tenha dificuldades na fala, nas expressões de ideias e sentimentos entre outros.

O autismo é uma síndrome
definida por alterações
presentes desde idades muito
precoces e que se caracteriza,
sempre, pela presença de
desvios nas relações
interpessoais, linguagem,
comunicação, jogos e
comportamento.
(SCHWARTZMAN
RODRIGUES, 2012, p. 10).

O autismo é uma condição permanente, isto é, acompanha o indivíduo por toda a vida, não tem cura, porém pode ter alterações durante o desenvolvimento da criança e se modificando com o passar dos anos. É denominado como "transtorno do espectro autista", ou "desordens do espectro autista" e recebe o nome de espectro, pois abrangem situações diferentes umas das outras, desde há mais leve a mais grave, sendo que estão englobadas no grupo de dificuldades de comunicação e relacionamento social. (Varella, 2015).

Sendo assim, denomina-se autismo:

Um transtorno com influência
genética, causado por defeitos
em partes do cérebro, como o
corpo caloso (que faz a
comunicação entre os dois
hemisférios), a amídala (que
tem funções ligadas ao
comportamento social e
emocional) e o cerebelo (parte
mais anterior dos hemisférios
cerebrais, os lobos frontais).
(RODRIGUES; OLIVEIRA;
DANDREA, 2013, p. 2).

A trajetória da história do autismo começa em 1943, pela primeira vez com o Doutor Leo Kanner que descreve o autismo como "um isolamento extremo desde o início da vida e um desejo obsessivo pela preservação da mesmice". (VOLKMAR; HUBNER; HALPERN, 2010). Em 1944 o mesmo assunto foi estudado pelo Doutor Hans Asperger, que apresentou definições similares com as de Kanner, mas que acrescentou ideias 
diferentes sobre esse transtorno, denominando-o síndrome de Asperger.

Esse tipo de "autismo" é considerado de alta funcionalidade, ou seja, são pessoas são autistas com inteligência preservada, isto é, tem um grau de funcionalidade maior em relação às outras pessoas com o mesmo transtorno, apresentam uma capacidade cognitiva superior, os denominado também como "autismo de alto desempenho". A partir disso, o Transtorno do Espectro Autista pode ser classificado em dois graus distintos:

Autismo Clássico:

O grau de comprometimento pode variar de muito. De maneira geral, os portadores são voltados para si mesmos, não estabelecem contato visual com as pessoas nem com 0 ambiente; conseguem falar, mas não usam a fala como ferramenta de comunicação. [...]. São crianças isoladas, que não aprendem a falar, não olham para as outras pessoas nos olhos, não retribuem sorrisos, repetem movimentos estereotipados, sem muito significado ou ficam girando ao redor de si mesmas e apresentam deficiência mental importante. (VARELLA, 2015).

Autismo de Alto Desempenho:

(Antes chamado de síndrome de Asperger), os portadores apresentam as mesmas dificuldades dos outros autistas, mas numa medida bem reduzida. São verbais e inteligentes. Tão inteligentes que chegam a ser confundidos com gênios, porque são imbatíveis nas áreas do conhecimento em que se especializam. Quanto menor a dificuldade de interação social, mais eles conseguem levar vida próxima à normal. (VARELLA, 2015).

Com base nos estudos das referências, Transtorno do Espectro Autista aparece nos dois primeiros anos, porém não é algo limitado. Esse transtorno afeta a comunicação (verbal e não verbal), como o atraso na fala e nos movimentos, através das ações físicas ou corporais e apresenta características como: características comportamentais gerais: impulsos, insônias, não atender quando é solicitado, não aceitação de uma visão do novo onde ele esteja presente, apresenta distância referente o afeto dos pais, não distingue situações de gravidade a sua volta, não utiliza expressão ou palavras para um momento de dificuldade ou emergência, apresenta momento de nervosismo sem motivos, pouco contanto visual, risadas extravagantes, insistência na repetição na qual não consegue interagir em novas rotinas.

Comprova-se que pessoas que possuem o transtorno do espectro autista têm a capacidade de se desenvolver como outras que não possuem este transtorno, pessoas estas como: Isaac Newton, Michelangelo, Charles Darwin e Bill Gates. 
Segundo RODRIGUES (2003, p. 4), as características da criança autista podem ser definidas pela sua idade, assim: 3 meses: não apresenta interesse fala humana, apenas concentra-se em movimentos repetidos; 4 à 6 meses: não estabelece contato visual, não interage com os familiares; 9 meses: executa poucos movimentos, não expressar sentimentos diferentes para situações diversas; 1 ano: não compreende pequenas ordens, os sons que emite não fazem parte do seu contexto; 1 ano e 6 meses: não apresenta empatia, não se identifica com o outro, pouco se comunica por meio de afeto; 2 anos: tem fascinação por objetos que giram, caminhar na ponta dos pés, girar em torno de si mesmo, acentuam-se os movimentos com as mãos em frente à face.

O tratamento para minimizar os sintomas pode ser feito através de medicamentos, fonoaudiologia, terapia comportamental, terapia de grupo e psicoterapia, lembrando que dependerá do que a pessoa apresenta do transtorno, isto é, pode ser "leve", ao mais "grave".

A seguir, algumas características que compõem a tríade do autismo:

Dificuldades de comunicação: Caracterizada pela dificuldade em utilizar com sentido todos os aspectos da comunicação verbal e não verbal: gestos, expressões faciais, linguagem corporal, ritmo e modulação na linguagem verbal. Dificuldade de socialização: Significa a dificuldade em relacionar-se com os outros, a incapacidade de compartilhar sentimentos, gostos e emoções e a dificuldade na discriminação entre diferentes pessoas. Dificuldade no uso da imaginação: Caracteriza-se por rigidez e inflexibilidade e se estende as varias áreas do pensamento, linguagem e comportamento da criança. (RODRIGUES, 2013, p. 2-3).

Através dos estudos, podemos ressaltar que as causas do autismo ainda são desconhecidas, porém, algumas hipóteses são definidas como anormalidades em alguma parte do cérebro, seja ela por fatores de hereditariedade, genética, ou até mesmo problemas na gestação ou na hora do parto, sendo que o diagnóstico é feito por um especialista, no caso o médico, que ao solicitar exames e propor testes consegue investigar as condições possíveis da criança ter a síndrome. Dificilmente o diagnóstico é conclusivo antes dos 2 anos de vida e geralmente quem observa primeiramente o comportamento da criança são os pais e professores, assim encaminham as observações para o especialista.

Portanto, o diagnóstico não é feito por um exame específico onde detecta a origem, mas são formulados através da observação do conjunto de sintomas identificados por um médico, sendo estes 14 sintomas, com a 
manifestação de 5 destes de forma repetitiva leva a hipótese do TEA. Assim, este artigo traz o referencial teórico existente sobre o conceito, as características do estudante com Transtorno do Espectro Autista, bem como, a apresentação de propostas pedagógicas para o trabalho do professor no ambiente escolar. Portanto, tem como foco a prática pedagógica dos professores da etapa do Ensino Fundamental I, com estudantes autistas que é necessário, intervenções pedagógicas diferenciadas.

Nesse sentido, a relevância deste artigo se justifica pela necessidade de refletir sobre a prática do professor em sala de aula numa escola inclusiva, de forma a apontar as limitações deste aluno e um possível trabalho a ser desenvolvido com ele, para que ocorra o acesso, a permanência e o sucesso desta criança na escola.

Trata-se de uma leitura atenta e sistemática, acompanhada de anotações e observações pessoais que serviram para a fundamentação teórica do estudo. Dessa forma, a análise foi feita de forma bibliográfica, qualitativa e descritiva, pois os autores deste artigo fizeram pesquisar em torno de livros, artigos, internet e outros meios científicos. Após o embasamento teórico realizado, apresentaram-se teorias sobre o tema e conclusões sobre as problemáticas apresentadas. Ao final deste estudo, buscaram-se soluções satisfatórias e que possam realmente auxiliar o professor em sala e assim, trazer benefícios aos interessados no assunto proposto.

A partir disto, o objetivo é orientar o leitor sobre o Transtorno do Espectro Autista (TEA), quanto ao conceito, características gerais e refletir sobre possíveis práticas pedagógicas necessárias para o trabalho com estudante com TEA.

\section{MÉTODO}

Para Lakatos e Marconi (2010, p. 83) “[...] o método é o conjunto das atividades sistemáticas e racionais que, com maior segurança e economia, permite alcançar o objetivo [...]" sendo assim, pode-se dizer que o método é os procedimentos e etapas que serão tomadas para se chegar a um objetivo.

O estabelecimento dos métodos de pesquisa é de extrema importância em um trabalho científico, pois estes ajudarão a tornar claro quais os procedimentos mais eficazes e menos arriscados para se ter resultados confiáveis e seguros.

O artigo foi estruturado utilizando pesquisa bibliográfica como método, no qual, foram selecionados e analisados materiais que 
deram suporte teórico, detalhando criteriosamente o universo do tema.

\section{RESULTADOS}

A educação é um desafio, porém, ainda maior para professores que trabalham com alunos que apresentam transtornos que interferem no ensino-aprendizagem, em especial o assunto deste artigo. Após as pesquisas e leituras feitas, aprendemos que cada criança é única e leva consigo suas particularidades, isto é, a aprendizagem acontece em diferentes momentos e formas, independente se o mesmo apresenta algum transtorno ou não.

A partir dos estudos realizados, compreende-se que, a longa trajetória do Transtorno do Espectro Autista, é uma síndrome permanente que afeta o desenvolvimento da criança em sua comunicação, sociabilização e imaginação, levando esta criança ao isolamento do meio em que está, criando um foco apenas em movimentos constantes e objetos repetidos, não estabelecendo vínculo e nenhum sentimento que o leve a expressar suas emoções.

O professor sendo o responsável pelo ensino cabe á ele seguir propostas pedagógicas de intervenção que melhor se adéquam as dificuldades apresentadas por cada um de seus alunos, propostas estas que auxiliam a criança no seu desenvolvimento como um todo.

Neste sentido, concluímos que é necessário se firmar o direito à educação para todos, oferecendo uma educação inclusiva para que se promova a inclusão dessas crianças, suprindo suas necessidades através de materiais, atividades, espaço físico e didática apropriados para que se atenda à toda a diversidade humana e assim consolidar uma educação de qualidade.

\section{DISCUSSÃO}

Partindo das conceituações e características apresentadas, faz-se necessário ao professor estabelecer intervenções com o objetivo de minimizar as dificuldades em relação à comunicação, sociabilização, e no uso da imaginação. (MELLO, 2007, p. 20-22).

Com base em estudos feitos através de alguns materiais pesquisados, outros fornecidos pela professora Marli Oliveira Rodrigues (orientadora) para a elaboração deste artigo, elencamos a seguir uma tabela com propostas de intervenções pedagógicas para práticas adequadas ao trabalho com estudante que apresenta o transtorno do 
espectro autista, com suas respectivas áreas de dificuldade.

\section{Comunicação}

- Informar possíveis alterações na rotina.

- $\quad$ Enunciar claramente as atividades.

- Manter o olhar a altura do olhar da criança.

- Mudar tons vocais ao se chamar a atenção (fino, grosso, alto, baixo).

- Afirmar atitudes, exemplo: Você está bravo? Contrario á: Por que você está bravo?

- Auxiliar na vocalização de sentimentos como Ah! Oh!

- Priorizar a representação por imagens e utilizar minimamente a comunicação por meio de palavras, pois a compreensão se torna mais acessível pelas imagens, gestos, objetos e outros.

- Reforçar o comportamento que é adequado, ignorando o inadequado.

- Hábitos que destroem ao redor não devem ser ignorados, o professor deve redirecionar este aluno para o que estava sendo feito em sala.

- Quando alterado, o professor deve acalmá-lo com poucas palavras e um simples toque suavemente sobre ele dizendo: "Calma, estou aqui".
- $\quad$ Após a familiarização da criança com o trabalho pedagógico, introduzir o "NÃO" para alguns pedidos dele.

- $\quad$ Oferecer e pedir ajuda.

- Persistência quando este aluno testa e tenta dominar o professor.

- Para demonstrar quem comanda, segurando o pulso do aluno.

\section{Sociabilização}

- Criar um vínculo, pois toda criança autista é única, singular, especial.

- $\quad$ Ser paciente, equilibrado e manso.

- Fazer carinho (afagar) durante a realização de uma atividade.

- $\quad$ Promover a interação com outros alunos por meio de atividades em grupo, jogos, passeios, etc.

- Ignorar os gritos ou levá-lo em outro ambiente para não interferir na aprendizagem dos demais alunos.

- Modificar a rotina caso o aluno com TEA insista em recusar a realizar as atividades.

- $\quad$ Sentá-lo próximo ao professor.

\section{Imaginação}

- $\quad$ Produzir com o aluno (CAA) 1 , ampliando sua capacidade comunicação dentro e fora da escola. 
- Desenvolver a $(\mathrm{LR})^{2}$ com frases fáceis e bem explicadas a fim do bom processamento da informação.

- Estimular a criança com movimentos: correr, pular, saltar, rolar.

- Realizar atividades com massa de modelar, ${ }^{1}$ cola colorida, tinta.

- Incentivar a imitação de sons provindos do ambiente que a mesma está inserida como telefone, gato, cachorro, buzina, etc.

- Incentivar a representação por meio de desenhos, músicas e brincadeiras de ações e sentimentos que estejam ocorrendo.

- $\quad$ Mantê-lo sempre ocupado.

- Priorizar atividades concretas para um melhor entendimento.

- Ao apresentar algum tipo de Estereotipia- movimentos repetitivos, ecolaliarepetição de palavras ou frases, interrompê-lo e dirigi-lo novamente para alguma atividade.

- $\quad$ Oferecer brinquedos interessantes.

- Noções de espaço precisam ser trabalhadas de forma concreta, prática.

- Promover a imitação de palmas, sino, etc.

- Trabalhar com a equoterapia, água, etc.

\footnotetext{
1 CAA - Comunicação Aumentativa e Alternativa é um conjunto de ferramentas e estratégias que o indivíduo utiliza para resolver os desafios de comunicação do cotidiano.

2 LR - Linguagem receptiva, responsável pela capacidade de compreender a palavra falada, é composta pelo feedback auditivo e visual.
}

\section{REFERÊNCIAS}

GONZALES,. R. Autismo Infantil. Disponível em: <http://www.tuasaude.com/autismo-infantil/> Acesso em: 21 abr. 2015

LAKATOS, E. M.; MARCONI, M. A. Metodologia do trabalho científico. 4.ed. São Paulo: Atlas, 2003.

LEITE. A. CAA - Comunicação Aumentativa e Alternativa: o que você precisa saber! Disponível em: <http://www.reab.me/caacomunicacao-aumentativa-e-alternativa-o-quevoce-precisa-saber/> Acesso em: 22 mar. 2015

LIMA. C. da S. e L.; ALMEIDA. M. A.Características da linguagem receptiva e expressiva de indivíduos deficientes mentais. In: CONGRESSO BRASILEIRO MULTIDISCIPLINAR DE EDUCAÇÃO ESPECIAL. 4., Disponível em: $<$ http://www.psiquiatriainfantil.com.br/congre ssos/uel2007/187.htm> Acesso em: 22 mar. 2015

MELLO, A. M. S. R. de. Autismo: guia prático. 5. ed. São Paulo: AMA; Brasília: CORDE, 2007.

MINAYO, M, C, S.; DESLANDES, S, F.; GOMES, R.; Pesquisa social: teoria, método e criatividade. 25. ed. Petrópolis, RJ: Vozes, 2007.

RODRIGUES, M. O..; OLIVEIRA, R. D. G.; DANDREA, S. V. M. TEA: Transtorno do Espectro Autista. Rede de informação e formação. Educação especial/ AEE- Educação infantil. Presidente Prudente, 2013.

RODRIGUES, M.de O. Transtornos Globais do Desenvolvimento (TGD). Presidente Prudente: Secretaria Municipal de Educação de Presidente Prudente/SP, 2012.

VARELLA. D. TEA - Transtorno do Espectro Autista II. Disponível em: 
$<$ http://drauziovarella.com.br/crianca-2/teatranstorno-do-espectro-autista-ii/> Acesso em:

22 mar. 2015

VOLKMAR, F.; HUBNER, M.; HALPERN, R. História do Autismo: 02 de abril- dia mundial da conscientização do autismo. Disponível em: $<$ http://autismoerealidade.org/informese/sobre-o-autismo/historia-do-autismo/>. Acesso em: 20 abr. 2015

Recebido para publicação em 20/05/2015

Revisado em 21/05/2015

Aceito em 22/05/2015 